\title{
THE EFFECTIVENESS OF VARIOUS ANTIBIOTICS IN METHYL METHACRYLATE
}

\author{
Paul D. Levin, Santa Cruz, California, United States of America \\ From the Dominican Santa Cruz Hospital, Santa Cruz, California
}

\begin{abstract}
The effectiveness of different antibiotics mixed with Simplex $\mathbf{P}$ has been tested in vitro. A laboratory model was designed to simulate the constant immersion of bone cement in tissue fluid. Clindamycin, and to a lesser extent Cephalothin, were shown to be effective when used in this manner against Staphylococcus aureus and epidermidis. Effective inhibition of Gram-negative organisms could not be demonstrated with any of the antibiotics tested. The addition of up to 3 grams of antibiotic powder per unit of $\mathbf{4 0}$ grams of Simplex P did not appear to alter the expansive properties of the cement. Such release of antibiotic as did occur was thought to be related to the slow absorption of water by the slightly porous methyl methacrylate.
\end{abstract}

Infection is the most serious complication after the use of methyl methacrylate for fixation of a prosthetic implant in bone and usually causes a complete failure of the procedure. The initial high incidence of infection associated with the use of cement has decreased considerably over the past few years. The improvement can be attributed to various factors, including the use of clean air surgical rooms (Charnley and Eftekhar 1969a), prophylactic systemic antibiotics (Boyd, Burke and Colton 1973; Bowers, Wilson and Greene 1973; Ericson, Lidgren and Lindberg 1973), topical antibiotics (Scherr, Dodd and Buckingham 1972), and impermeable drapes and surgical gowns (Charnley and Eftekhar 1969b). Nevertheless, a deep infection rate of about 1 per cent is still reported in several recent series (Amstutz 1970; Evarts, DeHaven, Nelson, Collins and Wilde 1973; Lazansky 1973; Murray 1973; Smith and Turner 1973). The hazard of infection increases with a history of previous operations (Lazansky 1970; Dupont and Charnley 1972) and is especially severe when there has been previous infection around the affected joint (Wilson, Salvati, Aglietti and Macys 1973). It has been shown that bacteria may remain viable in scar tissue for years and thus become reactivated when disturbed at a subsequent operation (Fitzgerald, Peterson, Washington, Van Scoy and Coventry 1973; Murray 1973).

An interesting technique of combining antibiotics directly in the methyl methacrylate cement has been described by Buchholz and his associates from their clinic in Hamburg (Buchholz and Engelbrecht 1970). He described the routine use of the method in over 2,000 cases, using for the most part either gentamicin or erythromycin. Recently, Buchholz reported at least a 75 per cent success rate after removal of the infected total prosthesis and simultaneous insertion of a new total hip replacement, using antibiotic-laced cement. He denies to date any sensitivity reactions to the antibiotic or any significant effect on the physical properties of the cement (Palacos) due to the presence of 0.5 to 1.0 gram of antibiotics in one unit (Buchholz and Gartman 1972; Wahlig and Buchholz 1972).

\section{MATERIALS AND METHODS}

The present study was undertaken to test the effectiveness of various antibiotics in Simplex $\mathbf{P}$ cement. The laboratory model was arranged to simulate the constant immersion of bone cement in body fluids.

It was arbitrarily decided to use in this study only those antibiotics which could be obtained in dry powder form. In clinical practice the antibiotics themselves would necessarily need to be sterile before mixing with methylmethacrylate powder. Clindamycin and gentamicin could not be obtained from the manufacturer in sterile form and were sterilised in ethylene oxide gas over a four-hour period; assays by the manufacturer then showed no decrease in potency of clindamycin and at the most a 10 per cent decrease in that of gentamicin. A standard agar gel diffusion technique was used for quantitative assay of the gas sterilised antibiotics (Oden, Stander and Weinstein 1964).

The antibiotics were mixed with Simplex B, nonradiopaque, in quantities of 0.5 to 3.0 grams per unit of 40 grams of cement powder. Before hardening of the cement, small coin-shaped discs 25 to 27 millimetres in diameter and 5 millimetres thick were fashioned and then stored under sterile conditions in one-litre jars of saline at 37 degrees Celsius to simulate immersion in tissue fluid at normal body temperature. After intervals of one or more days the discs were thoroughly washed by shaking in several changes of sterile saline, dried on paper and placed on culture plates to measure the degree of bacterial inhibition around them. Preliminary tests demonstrated that it was most important to rinse the discs thoroughly in several changes of saline; otherwise antibiotics from the saline solution could adhere back on to the surface of the cement and give an exaggerated degree of bacterial inhibition on the culture plates.

Staphylococcus aureus and Staphylococcus epidermidis were selected for testing against erythromycin, gentamicin, cephalothin, tetracycline and methicillin. Two Gram-negative organisms, E. coli and Pseudomonas aeruginosa, were used

Paul D. Levin, M.D., 1595 Soquel Drive, Santa Cruz, California 95065, United States of America. 
TABLE I

Millimetres of Inhibition with 1.5 Grams of ANtibiotic per UNIT of Cement

\begin{tabular}{|c|c|c|c|c|c|c|c|c|}
\hline & & \multicolumn{7}{|c|}{ Days } \\
\hline & & 1 & 5 & 10 & 20 & 30 & 40 & 60 \\
\hline \multirow[t]{2}{*}{ Erythromycin } & Staphylococcus epidermidis & 7 & 5 & 2 & 0 & 0 & 0 & 0 \\
\hline & Staphylococcus aureus & 7 & 6 & 3 & 0 & 0 & 0 & 0 \\
\hline \multirow[t]{2}{*}{ Cephalothin } & Staphylococcus epidermidis & 10 & 10 & 10 & 8 & 3 & 2 & 0 \\
\hline & Staphylococcus aureus & 10 & 10 & 10 & 10 & 8 & 6 & 3 \\
\hline \multirow[t]{2}{*}{ Clindamycin } & Staphylococcus epidermidis & 10 & 10 & 10 & 10 & 10 & 10 & 10 \\
\hline & Staphylococcus aureus & 10 & 10 & 10 & 10 & 10 & 10 & 10 \\
\hline \multirow[t]{2}{*}{ Gentamicin } & Staphylococcus epidermidis & 6 & 5 & 5 & 0 & 0 & $\mathbf{0}$ & 0 \\
\hline & Staphylococcus aureus & 2 & 0 & 0 & 0 & 0 & 0 & $\mathbf{0}$ \\
\hline \multirow[t]{2}{*}{ Tetracycline } & Staphylococcus epidermidis & 2 & 0 & 0 & 0 & 0 & 0 & 0 \\
\hline & Staphylococcus aureus & 2 & 0 & 0 & 0 & 0 & 0 & 0 \\
\hline \multirow[t]{2}{*}{ Methicillin } & Staphylococcus epidermidis & 2 & 0 & 0 & 0 & 0 & 0 & 0 \\
\hline & Staphylococcus aureus & 3 & 0 & 0 & 0 & 0 & 0 & 0 \\
\hline
\end{tabular}

for testing against gentamicin, colymycin, kanamycin, neomycin, polymyxin B and carbenicillin. The organisms were obtained in freeze-dried form (Hoffman-La Roche Corporation) and stored at 4 degrees Celsius until needed. Inoculation in trypsoy broth tubes for twenty-four hours started the organisms in an active growth phase before they were streaked on Muller-Hinton agar plates. Sensitivities of the organisms to the various antibiotics had been previously demonstrated by routine disc technique.

\section{RESULTS}

In every case there was inhibition of bacterial growth around the cement disc for a matter of hours. This effect could be ascribed to release of antibiotics directly from the surface of the cement. In only two cases did the effect persist to any degree for more than a few days. Clindamycin was the most effective, inhibiting bacterial growth for up to eighty days, even with the minimal quantity of 0.5 gram per unit of cement (Fig. 1). No other antibiotic showed such long-term inhibition, although cephalothin at 1.0 and 0.5 grams per unit showed effective inhibition for twenty-five or thirty days.

It was found early in the study that Gram-negative organisms were rather difficult to inhibit with this technique. For this reason the amount of antibiotic in each unit of cement was increased to three grams when the discs were tested against E. coli and pseudomonas. In spite of this there was no significant inhibition of pseudomonas by any of the antibiotics tested, although E. coli could be inhibited for up to four days (Table II). Absorption of water by the cement-After it became apparent that at least some of the antibiotics were being released over a period of time, it seemed appropriate to determine the mechanism. It seemed possible that absorption of water was occurring which would be measurable simply by interval weighing of the disc. For this reason, discs were weighed to the nearest hundredth of a gram and then placed in water, removed at intervals of a month, dried on paper and reweighed, over a thirteenmonth period. There was a consistent, slow gain in weight amounting to about 5 per cent by one year, virtually all of it during the first three months. Sectioning of the discs after one year showed a homogeneous darkening in colour compared with cement kept dry.

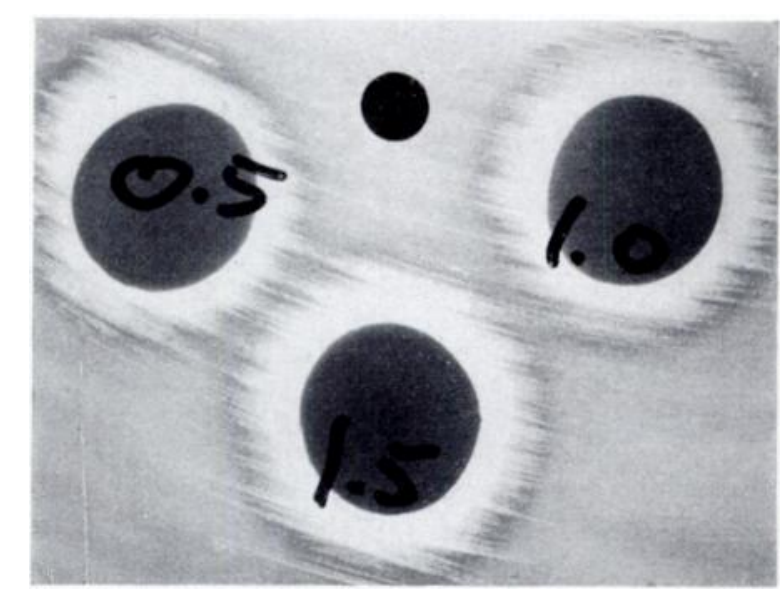

FIG. 1

Showing effective long-term inhibitory effect of clindamycin after immersion of cement discs for eighty days. The black dot is one centimetre in diameter.

Volumetric changes during hardening of the cement-An important question would appear to be whether or not the addition of a small amount of antibiotic powder changes the expansile properties of bone cement during 
TABLE II

Millimetres of Inhibition with 3 Grams of ANTibiotic Per UNit of Cement

\begin{tabular}{|c|c|c|c|c|c|c|c|}
\hline & & \multicolumn{6}{|c|}{ Hours } \\
\hline & & 0 & 1 & 24 & 48 & 72 & 96 \\
\hline \multirow[t]{2}{*}{ Gentamicin } & E. coli . & 10 & 10 & 9 & 5 & 3 & 2 \\
\hline & Pseudomonas aeruginosa & 10 & 10 & 2 & 0 & 0 & 0 \\
\hline \multirow[t]{2}{*}{ Carbenicillin } & E. coli . & 10 & 10 & 5 & 2 & 2 & 1 \\
\hline & Pseudomonas aeruginosa & 10 & 10 & 5 & 2 & 1 & 0 \\
\hline \multirow[t]{2}{*}{ Kanamycin } & E. coli . & 10 & 10 & 8 & 2 & 0 & 0 \\
\hline & Pseudomonas aeruginosa & 10 & 8 & 0 & 0 & 0 & 0 \\
\hline \multirow[t]{2}{*}{ Neomycin } & E. coli . & 10 & 10 & 3 & 3 & 0 & 0 \\
\hline & Pseudomonas aeruginosa & 10 & 7 & 0 & 0 & 0 & 0 \\
\hline \multirow[t]{2}{*}{ Polymyxin B } & E. coli . & 10 & 10 & 2 & 2 & 0 & 0 \\
\hline & Pseudomonas aeruginosa & 10 & 10 & 0 & 0 & 0 & 0 \\
\hline \multirow[t]{2}{*}{ Colymycin } & E. coli . & 10 & 10 & 2 & 2 & 0 & 0 \\
\hline & Pseudomonas aeruginosa & 10 & 9 & 0 & 0 & 0 & 0 \\
\hline
\end{tabular}

polymerisation. If shrinkage were increased there would be an increased risk of loosening of the implant. To test this possibility three antibiotics, cephalothin, erythromycin and clindamycin, were mixed in amounts of one to three grams per unit of cement. The expansion curves were tested by Charnley's method (1970); there was no alteration from the normal curve of ordinary Simplex $P$. In all instances the final volume of one unit of hardened cement was 0.5 cubic centimetres less than that of the soft cement before the onset of polymerisation.

\section{DISCUSSION}

The experimental results confirmed to some extent Buchholz's premise that certain antibiotics will slowly diffuse from methyl methacrylate and cause a local inhibition of bacterial growth. However, the very antibiotics that he favours, gentamicin and erythromycin, were found to be rather ineffective when used in Simplex $P$ (Figs. 2 and 3). True long-term release from the cement in amounts sufficient to inhibit bacterial growth was seen only with clindamycin and to a lesser extent with cephalothin. It should be reiterated that Buchholz's work has been with Palacos, of German manufacture. We are unable to state whether our results would have been significantly changed by using a different cement.

The mechanism of slow release of at least some of the antibiotics is a matter of conjecture but could be related to slight water absorption into the porosities of the cement. All antibiotics are hydrophylic, and once dissolved, could slowly diffuse to the surface of the cement. The mechanism of antibiotic release would necessarily differ from that of the poly-methyl methacrylate mono- mer, which is volatile rather than particulate and capable of egress from the porous cement without a diffusion medium.

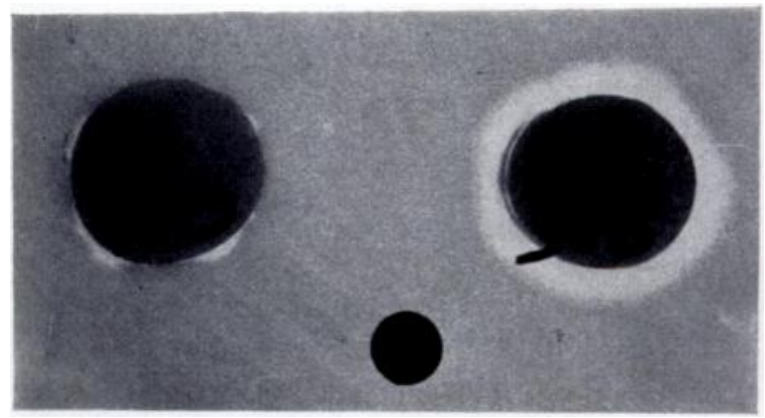

FIG. 2

Showing moderate effectiveness of three grams of gentamicin per unit of cement against $\mathrm{E}$. coli, but complete lack of activity of one gram per unit after immersion of the discs for fortyeight hours.

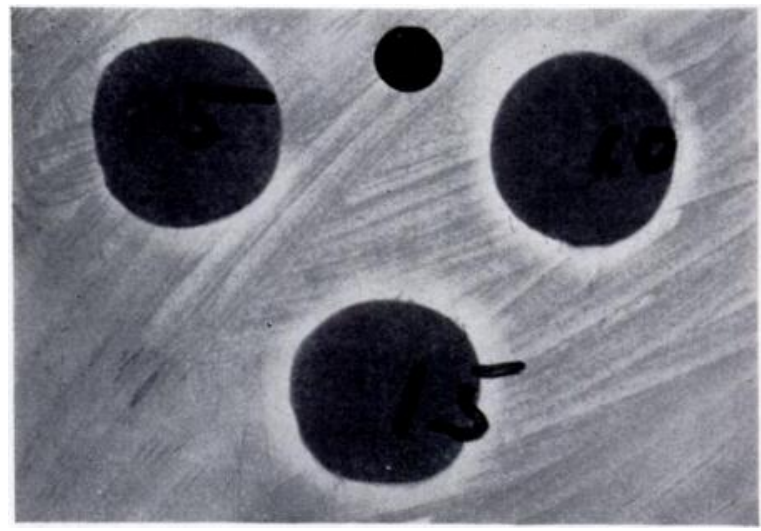

FIG. 3

Showing little inhibition of Staphylococcus epidermidis by erythromycin after immersion of the cement discs for ten days. 
There is no clinical evidence that local diffusion of antibiotics from cement is more effective than the use of the same antibiotic systemically. However, it is possible that such local action could have a cidal effect on bacteria trapped in minute cracks in the cement and out of reach of the systemic circulation. There is also the possibility that slow diffusion might prevent haematogenous infection around the cement, as occurred in the case recently reported by Mallory (1973). The most rational use of the Buchholz technique may be in instances of known previous infection in which the organism and its sensitivities are known.

The principal objection to incorporating antibiotics in cement is the inability to remove the drug in case of an allergic reaction. While it is apparent that only minute amounts would be released into the systemic circulation, it is also certain that only molecular quantities are needed to produce a true hypersensitivity reaction (DeSwarte 1972). The risk of such sensitivity would be reduced although not completely eliminated by pre-operative testing.

\section{REFERENCES}

Amstutz, H. C. (1970) Complications of total hip replacement. Clinical Orthopaedics and Related Research, 72, $123-137$.

Bowers, W. H., Wilson, F. C., and Greene, W. B. (1973) Antibiotic prophylaxis in experimental bone infections. Journal of Bone and Joint Surgery, 55-A, $795-807$.

Boyd, R. J., Burke, J. F., and Colton, T. (1973) A double-blind clinical trial of prophylactic antibiotics in hip fractures. Journal of Bone and Joint Surgery, 55-A, 1251-1258.

Buchholz, H. W., and Engelbrecht, H. (1970) Uber die Depotwirkung einiger Antibiotica bei Vermischung mit dem Kunstharz Palacos. Chirurg, 41, 511-515.

Buchholz, H. W., and Gartman, H.-D. (1972) Infektionsprophylaxe und operative Behandlung der schleichenden tiefen Infektion bei der totalen Endoprosthese. Chirurg, 43, 446-453.

Charnley, J. (1970) Acrylic Cement in Orthopaedic Surgery, pp. 27-31. Edinburgh and London: E. \& S. Livingstone.

Charnley, J., and Eftekhar, N. (1969a) Postoperative infection in total prosthetic replacement arthroplasty of the hip-joint, with special reference to the bacterial content of the air of the operating room. British Journal of Surgery, 56, 641-649.

Charnley, J., and Eftekhar, N. (1969b) Penetration of gown material by organisms from the surgeon's body. Lancet, 1, $172-173$.

DeSwarte, R. D. (1972) In Allergic Diseases-Diagnosis and Management, pp. 464-465. Edited by Roy Patterson. Philadelphia: J. B. Lippincott Co.

Dupont, J. A., and Charnley, J. (1972) Low-friction arthroplasty of the hip for the failures of previous operations. Journal of Bone and Joint Surgery, 54-B, 77-87.

Ericson, C., Lidgren, L., and Lindberg, L. (1973) Cloxacillin in the prophylaxis of postoperative infections of the hip. Journal of Bone and Joint Surgery, 55-A, 808-813, 843.

Evarts, C. M., DeHaven, K. E., Nelson, C. L., Collins, H., and Wilde, A. H. (1973) Interim results of Charnley-Müller total hip arthroplasty. Clinical Orthopaedics and Related Research, 95, 193-200.

Fitzgerald, R. H., Jun., Peterson, L. F. A., Washington, J. A., II, Van Scoy, R. E., and Coventry, M. B. (1973) Bacterial colonization of wounds and sepsis in total hip arthroplasty. Journal of Bone and Joint Surgery, 55-A, 1242-1250.

Lazansky, M. G. (1970) Complications in total hip replacement with the Charnley technic. Clinical Orthopaedics and Related Research, $72,40-45$.

Lazansky, M. G. (1973) Complications revisited: the debit side of total hip replacement. Clinical Orthopaedics and Related Research, 95, $96-103$.

Mallory, T. H. (1973) Sepsis in total hip replacement following pneumococcal pneumonia. Journal of Bone and Joint Surgery, 55-A, $1753-1754$.

Murray, W. R. (1973) Results in patients with total hip replacement arthroplasty. Clinical Orthopaedics and Related Research, 95, 80-90.

Oden, E. M., Stander, H., and Weinstein, M. J. (1964) Microbiological assay of gentamicin. Antimicrobial Agents and Chemotherapy-1963, 8-13.

Scherr, D. D., Dodd, T. A., and Buckingham, W. W., Jun. (1972) Prophylactic use of topical antibiotic irrigation in uninfected surgical wounds. Journal of Bone and Joint Surgery, 54-A, 634-640.

Smith, R. E., and Turner, R. J. (1973) Total hip replacement using methyl-methacrylate cement-an analysis of data from 3,482 cases. Clinical Orthopaedics and Related Research, 95, 231-238.

Wahlig, H., and Buchholz, H. W. (1972) Experimentelle und klinische Untersuchungen zur Freisetzung von Gentamycin aus einem Knochenzement. Chirurg, 43, 441-445.

Wilson, P. D., Jun., Salvati, E. A., Aglietti, P., and Macys, J. (1973) The results of total prosthetic replacement of the hip in the presence of known or suspected infection. Journal of Bone and Joint Surgery, 55-A, 1766. 